www.jmscr.igmpublication.org

Impact Factor 5.84

Index Copernicus Value: 83.27

ISSN (e)-2347-176x ISSN (p) 2455-0450

crossref DOI: _https://dx.doi.org/10.18535/jmscr/v5i6.178

\author{
Journal Of Medical Science And Clinical Research \\ IGM Publication \\ An official Publication of IGM Publication
}

\title{
Nutrient and Non-nutrient Antioxidant Evaluation of Maize (Zea mays L.)
}

\author{
Authors \\ Shivanki Aggarwal ${ }^{1}$, Sheel Sharma ${ }^{2}$ \\ ${ }^{1}$ Department of Food Science and Nutrition, Banasthali University, Rajasthan, India, 7042064912 \\ ${ }^{2}$ Department of Food Science and Nutrition, Banasthali University, Rajasthan, India, 9414543078 \\ Email: ${ }^{1}$ Shivankkiaggarwal88@gmail.com
}

\begin{abstract}
Food, historically known for nutrient composition, is gaining burgeoning interest as a ubiquitous source of bioactive, non-nutrient phytochemicals manifesting antioxidant synergism within body. Maize (Zea mays L.) has been explored in this study for its antioxidant vitamins content, phytochemical profile and antioxidant capacity. Preliminary phase of sample extraction was carried out by preparing aqueous-organic extracts from maize and, thereafter, these extracts were subjected to quantification of total phenols, flavonoids, antioxidant activities expressed in terms of DPPH (2,2-Diphenyl-1-picrylhydracyl) radical scavenging assay, ABTS (2,2'-Azinobis-(3-ethylbenzothiazoline-6-sulphonic acid) radical scavenging assay and FRAP (Ferric reducing antioxidant power) assay. Results revealed this cereal to be a potential food source of antioxidant network, mean values of $\beta$-carotene, total phenols, total flavonoids, DPPH, ABTS, FRAP being $167.44 \pm 2.05 \mu \mathrm{g} / 100 \mathrm{~g}, 216.66 \pm 20.82 \mathrm{mg}$ GAE/100g, 35.75 $\pm 2.88 \mathrm{mg} \mathrm{CE} / 100 \mathrm{~g}, 460 \pm 10 \mathrm{mg} \mathrm{TE} / 100 \mathrm{~g}$, $506.00 \pm 5.29 \mathrm{mg} \mathrm{TE} / 100 \mathrm{~g}$ and $223.47 \pm 18.05 \mathrm{mg} \mathrm{FeSO}_{4} / 100 \mathrm{~g}$ respectively. Though vitamin C content was not appreciable, but increased antioxidant activity of maize emanating from other antioxidant classes compensate for this deficit. Overall, intake of maize as a source of functional ingredient is recommended to promote health and halt insurmountable scenario of chronic, degenerative diseases.

Keywords: Maize, phenolics, vitamins, antioxidants, antiradical efficacy.
\end{abstract}

\section{Introduction}

The conceptual framework of balanced diet has recently been realized to not merely confined to nutritional components of food, but phytochemicals owing to their antioxidant properties have indispensable role to play in health promotion and disease prevention. Phytochemicals as bioactive, non-nutrient food fractions have been extolled to confer prudent protection against 120 degenerative diseases implicated to be rooted and aggravated due to oxidative arrest ${ }^{1}$. Food stuffs categorized in various food groups i.e. cereals, pulses and legumes, fruits and vegetables, nuts and oilseeds, besides being the historic dietary sources of macro- and micro-nutrients, provide a wide range of nutrient and non-nutrient antioxidant compounds. Maize (Zea Mays L.), in particular, has been studied to provide antioxidant network through phenolic acids, flavonols, anthocyanins, carotenoids, tocopherols, besides to being rich dietary source of energy, carbohydrate, fibre, B vitamins, magnesium, phosphorus, potassium, selenium ${ }^{2}$.

\section{Materials and Methods}

Sample procurement: Variety HQPM-1 for maize (Zea mays L., makka) was procured from Krishi 
Vigyan Center (ICAR), Banasthali University. Seeds were washed, dried in shade and then hand sorted to remove wrinkled seeds and foreign material and thereafter, stored in air tight container for further use.

Sample preparation: the sample was pulverized using home grinder and was used immediately for phenolic extraction.

\section{Quantification of nutrient antioxidants}

\section{Vitamin $\mathbf{C}$}

Principle: Vitamin C (L-ascorbic acid), after extraction in a mixture of metaphosphoric acid and dilute acetic acid, is estimated by titrating it with 2,6Dichlorophenol indophenol dye solution. Oxidized form of this dye has a blue and red colour in alkaline and acidic medium respectively while reduced form has no colour (leuco form). Upon redox reaction with vitamin $\mathrm{C}$, the dye generates its leuco form.

Procedure: Sample extraction- $1 \mathrm{Og}$ sample was homogenized with about $50 \mathrm{ml}$ of $5 \%$ metaphosphoric-10\% acetic acid solution. Then it was transferred into a $100 \mathrm{ml}$ volumetric flask and was shaken gently until a homogeneous dispersion was obtained. Then it was diluted upto the mark by 5\% metaphosphoric-10\% acetic acid solution. Then the solution was filtered and the clear filtrate was collected for the determination of vitamin $\mathrm{C}$ in that sample.

Sample analysis- The burette was filled with dye solution (52mg of sodium salt of the dye $+42 \mathrm{mg}$ of sodium bicarbonate in water and made upto $500 \mathrm{ml}$ ). $20 \mathrm{ml}$ of standard vitamin C solution $(10 \mathrm{mg} / \mathrm{L}$ in $5 \%$ metaphosphoric-10\% acetic acid solution) was transferred into a titration flask and titrated against the dye solution to the appearance of a light pink color. Noted down the volume. Similarly, 20ml of test solution was titrated against the dye solution and value was noted ${ }^{2}$.

Calculations: Since the concentration of $20 \mathrm{ml}$ standard vitamin C solution is $200 \mu \mathrm{g}$, vitamin C content in $100 \mathrm{ml}$ or $10 \mathrm{~g}$ test sample is calculated as $\frac{Y}{X} \times 1 \mathrm{mg}$, where $\mathrm{Y}=$ amount $(\mathrm{ml})$ of dye causing oxidation of test vitamin $\mathrm{C}$ solution $(20 \mathrm{ml})$ and $\mathrm{X}=$ amount (ml) of dye causing oxidation of standard vitamin C solution (20ml).

\section{2. $\beta$-carotene}

Procedure: $10 \mathrm{~g}$ of macerated sample was placed into a conical flask containing $50 \mathrm{ml}$ of $95 \%$ ethanol and maintained at a temperature of $70-80^{\circ} \mathrm{C}$ in a water bath for 20 minutes with periodic shaking. The supernatant was decanted, allowed to cool and its volume was measured by means of a measuring cylinder and recorded as initial volume. The ethanol concentration of the mixture was brought to $85 \%$ by adding $15 \mathrm{ml}$ of distilled water and it was further cooled in a container of ice water for about 5 minutes. The mixture was transferred into a separating funnel and $25 \mathrm{ml}$ of petroleum ether was added and the cooled ethanol was poured over it. The funnel was swirled gently to obtain a homogeneous mixture and it was later allowed to stand until two separate layers were obtained. The bottom layer was run off into a beaker while the top layer was collected into a $250 \mathrm{ml}$ conical flask. The bottom layer was transferred into the funnel and reextracted with $10 \mathrm{ml}$ petroleum ether for 5-6 times until the extract became fairly yellow. The entire petroleum ether was collected into $250 \mathrm{ml}$ conical flask and transferred into separating funnel for reextraction with $50 \mathrm{ml}$ of $80 \%$ ethanol. The final extract was measured, its absorbance was measured using a spectrophotometer at a wavelength of $436 \mathrm{~nm}^{4}$.

Calculations: Equation of Bear-Lamberts law was applied i.e. $\mathrm{A}=\mathrm{ECL}$ or $\mathrm{C}=\mathrm{A} / \mathrm{EL}$; where $\mathrm{C}=$ concentration of carotene, $\mathrm{A}=$ absorbance, $\mathrm{E}=$ extinction coefficient, $\mathrm{L}=$ thickness of cuvettes $(1$ $\mathrm{cm}), \mathrm{E}=1.25 \times 10^{4} \mu \mathrm{g} / \mathrm{l}$

Phytochemical estimation and antioxidant activity assessment

\section{Sample extraction}

Pulverized samples $(0.25 \mathrm{~g})$ were placed in test tubes with $10 \mathrm{ml}$ of methanol/water $(50: 50, \mathrm{v} / \mathrm{v})$. The $\mathrm{pH}$ was adjusted to 2 using $2 \mathrm{M} \mathrm{HCl}$. The tubes were thoroughly shaken, using orbital shaker, at room temperature for $1 \mathrm{hr}$, and then centrigued at $2500 \mathrm{~g}$ for 10 mins. Supernatants were collected in clean dry test tubes. Then the residues were extracted 
again with $10 \mathrm{ml}$ of an acetone/water mixture (70:30, v/v). The methanol and acetone extracts were combined and subsequently used for various assays. Extracts produced in duplicate. In case of non-usage of extracts on the same day, they were stored at $4{ }^{\circ} \mathrm{C}$ and used within a week for all analysis 5 .

\section{Phytochemical analysis}

A. Total phenolic content (TPC)

Principle: It is based on the single electron transfer (SET) in alkaline medium $\left(7 \% \mathrm{NaCO}_{3}\right)$ from phenolic compound to molybdenum, forming blue complex which is measured spectrophotometrically at $750-765 \mathrm{~nm}$.

Procedure: The mixture of sample solution $(0.1$ $\mathrm{ml})$, deionized water $(6 \mathrm{ml})$, FCR solution $(0.5 \mathrm{ml})$, $7 \% \mathrm{NaCO}_{3}(1.5 \mathrm{ml})$ was vortexed for $1 \mathrm{~min}$ and incubated for $8 \mathrm{~min}$ at room temperature. Then a dose of $1.9 \mathrm{ml}$ of deionized water was added. The mixture was allowed to stand for $2 \mathrm{~h}$ at room temperature. The absorbance was measured at 765 nm against blank ${ }^{6}$.

Calculations: TPC was expressed as gallic acid equivalent (mg GAE/100g sample) through the calibration curve of gallic acid. Linearity range of the calibration curve was 100 to $1000 \mu \mathrm{g} / \mathrm{ml}$.

\section{B. Total flavonoid content (TFC)}

Principle: Aluminum chloride forms acid complexes with the C-4 keto group and either the C3 or C-5 hydroxyl group of flavones and flavonois. In addition, aluminum chloride forms acid labile complexes with orthodihydroxyl groups in the A or B ring of flavonoids.

Procedure: $0.5 \mathrm{ml}$ of sample was mixed with 2.5 $\mathrm{ml}$ of deionized water in a test tube followed by adding $0.15 \mathrm{ml}$ of $5 \%$ sodium nitrite $\left(\mathrm{NaNO}_{2}\right)$ solution. After 6 minutes, $0.3 \mathrm{ml}$ of $10 \%$ aluminum chloride hexahydrate $\left(\mathrm{AlCl}_{3} \cdot 6 \mathrm{H}_{2} \mathrm{O}\right)$ solution was added and allowed to stand for another 5 minutes before adding $0.1 \mathrm{ml}$ of $1 \mathrm{M} \mathrm{NaOH}$. The mixture was brought to $5 \mathrm{ml}$ with the addition of $0.55 \mathrm{ml}$ of deionized water and mixed well. The absorbance was measured immediately against the blank (the same mixture without the sample) at $510 \mathrm{~nm}$ using UV-spectrophotometer ${ }^{6}$.

Calculations: TFC was expressed as catechin equivalents (mg CE/100g sample). Linearity range of catechin calibration curve was $62.5-375 \mu \mathrm{g} / \mathrm{ml}$.

\section{Antioxidant activity analysis}

A. DPPH radical scavenging activity

Principle: It is based on antioxidant-catalyzed reduction of purple-colored DPPH radical to its yellow-colored non-radical form which is measured spectrophotometrically at $517 \mathrm{~nm}$.

Procedure: A dose of $0.2 \mathrm{ml}$ of tested legume extract was added to $7.6 \mathrm{ml}$ ethanol solution of DPPH radical (final concentration was $0.1 \mathrm{mM}$ ). The mixture was shaken vigorously for $1 \mathrm{~min}$ by vortexing and left to stand at room temperature in the dark for $30 \mathrm{~min}$. Thereafter, the absorbance was measured at $517 \mathrm{~nm}$ against ethanol blank ${ }^{6}$.

Calculations: DPPH scavenging activity was expressed as trolox equivalents (mg TE/100g sample). Linearity range of trolox calibration curve was $\mathbf{0 . 0 5} \mu \mathrm{M}$ to $0.4 \mathrm{mM}$ trolox.

\section{B. ABTS radical scavenging activity}

Principle: It is based on antioxidant inhibition of the absorbance of blue-green coloured ABTS radical, generated via persulfate-induced ABTS oxidetion, measured spectrophotometrically at $734 \mathrm{~nm}$.

Procedure: The stock solutions included $7.4 \mathrm{mM}$ ABTS solution and $2.6 \mathrm{mM}$ potassium persulfate solution. The working solution was then prepared by mixing the two stock solutions in equal quantities and allowing them to react for $12 \mathrm{~h}$ at room temperature in the dark. The solution was then diluted by mixing $1 \mathrm{ml} \mathrm{ABTS} \bullet^{+}$solution with $30 \mathrm{ml}$ methanol to obtain an absorbance of $1.1 \pm 0.02$ units at $734 \mathrm{~nm}$ using the spectrophotometer. In sample $(0.3 \mathrm{ml})$, prepared ABTS $\bullet^{+}$solution $(5.7 \mathrm{ml})$ was added and kept it for 2 hrs in a dark condition. Then the absorbance was taken at $734 \mathrm{~nm}$ using spectrophotometer ${ }^{7}$.

Calculations: ABTS scavenging activity was expressed as trolox equivalents (mg TE/100g sample). Linaerity range of trolox calibration curve was $0.1-0.7 \mathrm{mM}$ trolox. 


\section{FRAP assay}

Principle: It is based on antioxidant-catalyzed reduction of ferric-TPTZ complex (colorless) to ferrous form (intensely blue coloured) which is measured spectrophotometrically at $593 \mathrm{~nm}$

Procedure: The working FRAP reagent was prepared by mixing 10 volumes of $300 \mathrm{mM}$ acetate buffer, $\mathrm{pH} 3.6$, with 1 volume of $10 \mathrm{mM}$ TPTZ (2,4,6-Tripyridyl-s-triazine) in $40 \mathrm{mM} \mathrm{HCl}$ and with 1 volume of $20 \mathrm{mM} \mathrm{FeCl} 3 \times 6 \mathrm{H} 2 \mathrm{O}$ (ferric chloride hexahydrate). Prepared working FRAP reagent was warmed to $37 \circ \mathrm{C}$. In $6 \mathrm{ml}$ FRAP reagent, $0.2 \mathrm{ml}$ of sample and $0.6 \mathrm{ml}$ of deionized water were added and the absorbance was taken at $593 \mathrm{~nm}$ against reagent blank after 4 mins $^{6}$.

Calculations: FRAP value was expressed as $\mathrm{Fe}^{2+}$ (Iron (II) sulfate heptahydrate or ferrous sulfate) equivalent (mg FRAP/100g sample). Linearity range of the calibration curve was $0.1-0.9 \mathrm{mM}$.

\section{Result and Discussion}

Maize (Zea mays L.) is being endeavoured in this study to estimate nutrient antioxidants, phenolic fractions and associated antioxidant activity. Antioxidant vitamins estimation, as shown in table 1 , has shown maize to be a good dietary source of $\beta$-carotene, although vitamin $\mathrm{C}$ was found in trace amounts. The vitamin $\mathrm{C}$ and $\beta$-carotene results are in agreement with studies cited by authors ${ }^{8,9}$. Besides $\beta$-carotene, other carotenoids cited to be present in maize are lutein, zeaxanthin, $\alpha$-carotene, $\beta$-cryptoxanthin ${ }^{10}$. As vitamin E classes, both $\alpha$ - and $\gamma$-tocopherols are documented to predominate in maize $^{11}$. Pertaining to phytochemical profile presented in table 2, total phenols and flavonoids were found to be in good proportions. These values are in accordance with work done by authors ${ }^{12,13}$. Studies have reported wide range of Phenolic antioxidants to be located in maize comprising phenolic acids viz. protocatechuic, p-hydroxy benzoic, vanillic, syringic, ferulic, caffeic, pcoumaric, chlorogenic acids; flavonols viz. kaempferol, quercetin, rutin, morin, kaempferol; flavanols leucopelargonidin ${ }^{14,15,16}$.The antiradical efficacy of maize against DPPH and ABTS radicals and its reducing power exhibited by FRAP, shown in table 3 , revealed significant values that are consistent with the studies ${ }^{17,18}$. This signifies that maize holds the capacity to scavenge free radicals in biological systems too and can protect us from various degenerative diseases known to seed and snowball from oxidative stress. In vivo studies on rat models corroborate maize to mitigate oxidative stress via upregulation of endogenous antioxidant enzymes i.e. glutathione peroxidase, catalase, superoxide dismutase and total peroxidase; and suppression of lipid peroxidation, attributed to the presence of anthocyanins, flavonols and phenolic $\operatorname{acids}^{19}$.

Table 1: Antioxidant vitamins (vitamin $\mathrm{C}$ and $\beta$ carotene) content of maize

\begin{tabular}{|l|c|}
\hline Vitamin $\mathrm{C}(\mathrm{mg} / 100 \mathrm{~g})$ & B-carotene $(\mu \mathrm{g} / 100 \mathrm{~g})$ \\
\hline $0.92 \pm 0.02$ & $167.44 \pm 2.05$ \\
\hline
\end{tabular}

Table 2: Phytochemical content of aqueous-organic extracts of Maize

\begin{tabular}{|l|c|}
\hline $\begin{array}{l}\text { Total phenols (mg } \\
\text { GAE/100g) }\end{array}$ & $\begin{array}{c}\text { Total flavonoids (mg } \\
\text { CE/100g) }\end{array}$ \\
\hline $216.66 \pm 20.82$ & $35.75 \pm 2.88$ \\
\hline
\end{tabular}

Values are mean \pm standard deviation, $\mathrm{n}=3$

Table 3: Antioxidant activity of aqueous-organic extracts of Maize

\begin{tabular}{|l|c|c|}
\hline $\begin{array}{l}\text { DPPH } \\
\text { TE/100g) }\end{array}$ & ABTS (mg & FRAP (mg \\
\hline $460 \pm 10$ & TE/100g) & FeSO $\left._{4} / 100 \mathrm{~g}\right)$ \\
\hline
\end{tabular}

Values are mean \pm standard deviation, $n=3$

\section{Conclusion}

Maize (Zea mays L.), besides being a rich source of energy, carbohydrates, dietary fibre and micronutrients, is being advocated to be rich in nonnutrient components too associated with potent antioxidant activity and promising biological effects. Estimation of antioxidant vitamins, phytochemical profiles and antioxidant activity assessment of maize in this study concludes that this cereal carries appreciable antioxidant activity, making it a food ingredient of choice to antagonise the deleterious mechanisms in body linked with oxidative stress. 


\section{References}

1. Liu RH. Potential synergy of phytochemicals in cancer prevention: mechanism of action. Journal of Nutrition. 2004, 134: 3479S-3485S.

2. Enyisi I S, Umoh VJ, Whong CMZ, Abdullahi IO and Alabi O. Chemical and nutritional value of maize and maize products obtained from selected markets in Kaduna State, Nigeria.African Journal of Food Science and Technology. 2014, 5(4): 100-104.

3. Raghuramulu N, Nair KM, Kalyanasundaram S. A Manual of Laboratory Techniques, NIN, Indian Council of Medical Research, Hyderabad, 2003, 56-58, 6061,176-184.

4. Mustafa, Y. and Babura, S.R., Determination of carbohydrate and $\beta$ carotene content of some vegetables consumed in Kano Metropolis, Nigeria, Bayero Journal of Pure and Applied Sciences, (2009), 2(1), 119-121.

5. Pérez-Jiménez, J., Arranz, S., Tabernero, M., Díaz-Rubio, M.E., Serrano, J., Goni, I., and Saura-Calixto, F. Updated methodology to determine antioxidant capacity in plant foods, oils and beverages: Extraction, measurement and expression of results, Food Research International, 2008, 41, 274-285.

6. Xu, B.J. and Chang, S.K.C. A comparative study on phenolic profiles and antioxidant activity of legumes as affected by Extraction solvents. 2007, Journal of Food Science, 72(2), S159-S166.

7. Thaipong, K., Boonprakob, U., Crosby, K., Cisneros-Zevallos, L., and Byrne, D.H. Comparison of ABTS, DPPH, FRAP and ORAC assays for estimating antioxidant activity from guava fruit extracts, Journal of Food composition and analysis, 2006, 19, 669-675

8. Gopalan, C., Rama Shastri, B.V. and Balasubramanian, S.C. Revised and updated by NarasingaRao, B.S., Deosthale, Y.G. and
Pant, K.C. Nutritive Value of Indian Foods, (2002 Edition), National Institute of Nutrition, Hyderabad, India

9. KandlakuntaB, Rajendran A and Thingnganing L. Carotene content of some common cereals, pulses, vegetables, spices and condiments and unconventional sources of plant origin. Food Chemistry. 2008, 106: 85-89.

10. BacchettiT, Masciangelo S, Micheletti A and Ferretti G.Carotenoids, Phenolic Compounds and Antioxidant Capacity of Five Local Italian Corn (Zea Mays L.) Kernels. 2013, 3(6): 1-4

11. Nuss ET and Tanumihardjo SA. Maize: A Paramount Staple Crop in the Context of Global Nutrition. Comprehensive Reviews in Food Science and Food Safety. 2010, 9:417-436.

12. Prajapati MR, Patel V, Parekh T and Subhash R. Effect of in bio-processing in antioxidant activity of selected cereals. Asian Journal of Plant Science and Research. 2013, 3(2): 66-72.

13. Alka S, Neelam Y and Shruti S. Evaluation of In vitro antioxidant profile of selected cereals. International Journal of Pharma and Bio Sciences. 2013, 4 (3): (B) 659-667.

14. KaurKD, Jha A, Sabikhi L and Singh AK. Significance of coarse cereals in health and nutrition. Journal of Food Science and Technology. 2014, 51(8): 1429-1441.

15. Dykes L and Rooney LW. Phenolic compounds in cereal grains and their health benefits. Cereal Foods World. 2007, 52(3): 105-111.

16. Ramos-Escudero F, Muñoz AM, AlvaradoOrtíz C, Alvarado A and Yañez JA. Purple Corn (Zea mays L.) Phenolic Compounds Profile and Its Assessment as an Agent Against Oxidative Stress in Isolated Mouse Organs. Journal of Medicinal Food. 2012, 15(2): 206-215.

17. Zilic S, Serpen A, Akillioglu G, Gokmen V and Vancetovic. Phenolic compounds, 
carotenoids, anthocyanins, and antioxidant capacity of colored Maize (Zea mays L.) kernels. Journal of Agricultural and Food Chemistry. 2012, 60: 1224-1231.

18. Prajapati MR, Patel V, Parekh $\mathrm{T}$ and Subhash R. Effect of in bio-processing in antioxidant activity of selected cereals. Asian Journal of Plant Science and Research. 2013, 3(2): 66-72.

19. ThiraphatthanavongP, Wattanathorn J, Muchimapura S, Thukham-mee W Wannanon P, Tong-un T, Suriharn B and Lertrat K. Preventive Effect ofZea mays L. (Purple Waxy Corn) onExperimental Diabetic CataractBioMedical Research International. 2014, 507435: 1-8.

\footnotetext{
Abbreviations

DPPH: 2,2-Diphenyl-1-picrylhydracyl, ABTS: 2,2'Azinobis-(3-ethylbenzothiazoline-6-sulphonic acid), FRAP: Ferric reducing antioxidant power, TPC: Total phenolic content, TFC: Total flavonoid content, TE: Trolox equivalent, GAE: Gallic acid equivalent, $\mathrm{CE}$ : Catechin equivalent, TROLOX: 6hydroxy-2,5,7,8-tetramethylchroman-2-carboxylic acid
} 